\title{
Macular dazzling test on normal subjects
}

\author{
F GOMEZ-ULLA, O LOURO AND M MOSQUERA
}

From the Department of Ophthalmology, University of Santiago de Compostela, General Hospital of Galicia, Spain

SUMMARY The macular dazzling test was performed on 240 healthy eyes, classified into six groups according to the ages of the subjects. The test was used to assess both long distance and short distance vision with a simultaneous study of the influence of mydriasis and miosis.

The MDT is a test easy to perform, requires a minimum of co-operation by the subject, and gives repeatable results. The MDT values increase significantly as the age of the subject increases. The sex of the subject has no influence on it, and there are no significant differences between a subject's right and left eyes. Mydriasis does not affect the MDT, but miosis reduces the recovery period. All the values are statistically greater for long distance vision than for short distance vision.

One of the methods for the subjective exploration of the retina (visual acuity, Amsler table, static perimetry, colour vision) is the Bailliart test. ${ }^{1}$ This test was formulated to determine the functional macular reaction by dazzling the retina and then measuring the length of time which the subject takes to regain the level of visual acuity he had prior to the dazzling. Since what is actually being explored with this method is the function of the macula, we refer to it as the macular dazzling test (MDT). One of the characteristics of the test is the use of induced macular fatigue, like the induced fatigue used for heart studies. $^{2}$

The purpose of the work reported here was to standardise the MDT technique and thus to typify the results for normal subjects, not only for long distance vision-as previous authors have donebut also for short distance vision, in addition to studying the influence of the diameter of the pupil on obtaining results.

\section{Materials and methods}

We have performed the MDT on 240 healthy eyes. The ages of the subjects ranged from 10 to 69 years, the ratio of the sexes being 50:50. The subjects were divided into age groups as follows: from 10 to 19, 20 to 29,30 to 39,40 to 49,50 to 59 , and 60 to 69 years. Each age group contained 20 subjects, 10 male and 10

Correspondence to Dr D Francisco Gómez-Ulla de Irazazábal, Hospital General de Galicia, Departamento de Oftalmología, c/Galeras s/n, Santiago de Compostela, Spain. female. In all cases their visual acuity was equal to or greater than $20 / 25$, with or without optical adjustment, and we accepted a refraction defect of not more than 3 dioptres of hypermetropia, myopia, or astigmatism.

To produce the dazzle, a Minolta electronic flash, guide no. 20 in meters with 100 ASA, with a 1/2000s flash, was used. A Heuer chronometer was used to measure the recovery time for visual acuity following the dazzling.

Long distance visual acuity was explored through the use of Snellen optotypes and short distance vision by means of the Parinaud test. To perform the MDT we followed the method proposed by Lemrini and Carreras. ${ }^{3.5}$ The exploration was systematically begun on the right eye, and later continued on the left eye.

The subject was instructed to look directly into the light source, and the dazzle was produced by the flash apparatus located $1 \cdot 5-2 \mathrm{~cm}$ from the cornea. At the instant at which the dazzle was produced the chronometer was set in motion, and from this moment on the recording of the recovery time began, with the chronometer stopping at the moment when the subject reached the same visual acuity (same line on the optotype) as before the dazzling. The test was repeated for short distance vision, the short distance optotypes being used as a point of reference.

We have studied the influence of the dilatation of the pupil and of miosis in relation to the test results in 65 subjects of the sample. For this purpose two drene 209 
eyes of these 65 subjects, and two drops of $2 \%$ pilocarpine were put into their left eyes. They underwent the same procedure described above, when the right pupils reached a diameter of $7-8 \mathrm{~mm}$ and the left a diameter of 2-3 mm.

\section{Results}

The MDT recovery time was statistically $(\mathrm{p}<0 \cdot 001)$ longer for long distance vision $(\bar{x}=15.49 \mathrm{~s})$ than for short distance vision $(\bar{x}=11.61 \mathrm{~s})$ (Table 1$)$. The range of variation observed for long distance vision was found to be 7 seconds (a total of 5 cases-2.1\% between the second and third decades of their lives) and 35 seconds ( 3 cases- $1 \cdot 25 \%$ - distributed among the first, fifth, and sixth decades). A similar range was also observed for short distance vision: 5 seconds for the minimum value (two cases in the second and third decades $-0.8 \%$ ) and 50 seconds for the maximum value in one case- $0.4 \%$-in the fifth decade.

\section{Table 1 MDT results on a normal population}

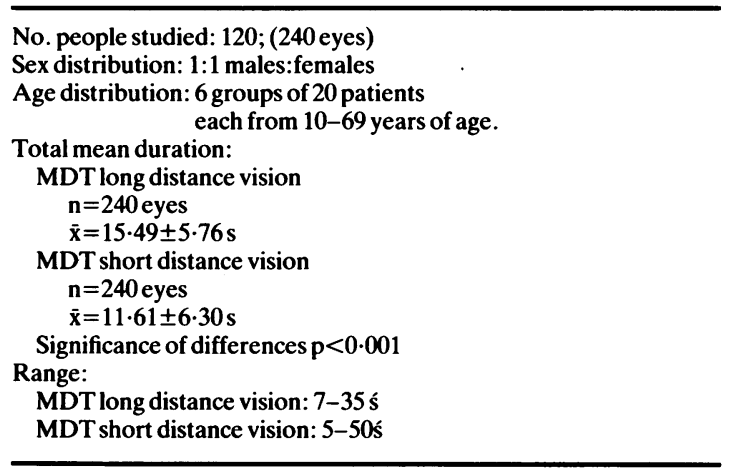

Table 2 MDT results related to eye laterality (right or left eye)

MDT long distance vision:
RE: $\quad n=120$ eyes
$\quad \bar{x}=15 \cdot 89 \pm 6 \cdot 22 \mathrm{~s}$
range: $7-35 \hat{s}$
LE: $\quad n=120$ eyes
$\quad \bar{x}=15 \cdot 10 \pm 5 \cdot 24 \mathrm{~s}$
$\quad$ range: $7-35 s$
Significance of differences: $p>0 \cdot 1$
MDT in short distance vision:
RE: $\quad n=120$ eyes
$\quad \bar{x}=11 \cdot 48 \pm 6 \cdot 09 \mathrm{~s}$
range: $5-45 s$
LE: $\quad n=120$ eyes
$\quad \bar{x}=11 \cdot 73 \pm 6 \cdot 54 \mathrm{~s}$
Significance of differences: $p>0 \cdot 1$
Significance of differences between MDT (Long) and MDT (short):
RE: $p<0 \cdot 001$
LE: $p<0 \cdot 001$

The values obtained from the MDT were similar in the right and left eyes of the subjects, both for long distance vision and for short distance vision. Nevertheless some differences were apparent when a comparison is made between the figures for long distance vision and short distance vision, with those for short distance vision being significantly lower (Table 2).

Differences in MDT values between the sexes were not observed; the figures for both male and female subjects were similar for long distance vision, though there was a slight difference in their short distance vision (Table 3).

The recovery time for the MDT showed a clear tendency towards increase with aging, both for long distance vision and short distance vision, the means being accompanied by a general increase of standard deviations (Table 4). We have also demonstrated the existence of a high correlation between the means and the standard deviations of the different age groups (Figs. 1A and 1B). This increase in the MDT with an increase in age became clearer when a comparison was made between the values for the

Table 3 MDT results related to sex difference

\begin{tabular}{|c|c|}
\hline $\begin{array}{l}\text { MDT long distance vision: } \\
\text { Males: } \\
\quad \mathrm{n}=120 \text { eyes } \\
\overline{\mathrm{x}}=15 \cdot 03 \pm 5 \cdot 40 \mathrm{~s} \\
\text { range: } 7-35 \mathrm{~s} \\
\text { Significance of differences }\end{array}$ & $\begin{array}{l}\text { Females: } \\
\quad n=120 \text { eyes } \\
\quad \bar{x}=15 \cdot 95 \pm 6 \cdot 08 \mathrm{~s} \\
\text { range: } 8-35 s \\
p>0 \cdot 1\end{array}$ \\
\hline $\begin{array}{l}\text { MDT short distance vision: } \\
\text { Males: } \\
\quad n=120 \text { eyes } \\
\overline{\mathrm{x}}=10 \cdot 83 \pm 4 \cdot 99 \mathrm{~s} \\
\text { range: } 5-50 \mathrm{~s} \\
\text { Significance of differences }\end{array}$ & $\begin{array}{l}\text { Females: } \\
\quad n=120 \text { eyes } \\
\quad \bar{x}=12 \cdot 38 \pm 7 \cdot 33 \mathrm{~s} \\
\text { range: } 5-45 s \\
p<0 \cdot 01\end{array}$ \\
\hline
\end{tabular}

Table 4 MDT duration in age groups

\begin{tabular}{lccc}
\hline \multicolumn{2}{l}{ MDT long distance vision (seconds) } & \\
\cline { 1 - 2 } Age group & $\bar{x} \pm S D$ & Range \\
\hline $10-19$ & $13 \cdot 88 \pm 5 \cdot 19$ & $8-35$ \\
$20-29$ & $12 \cdot 78 \pm 3 \cdot 81$ & $7-21$ \\
$30-39$ & $13 \cdot 47 \pm 3 \cdot 41$ & $7-20$ \\
$40-49$ & $15 \cdot 25 \pm 4 \cdot 96$ & $8-26$ \\
$50-59$ & $18 \cdot 13 \pm 7 \cdot 14$ & $8-35$ \\
$60-69$ & $19 \cdot 44 \pm 6 \cdot 07$ & $11-35$ \\
\hline MDTshort distance vision & $($ seconds) & \\
\hline Age group & $\bar{x} \pm S D$ & Range \\
\hline $10-19$ & $8.93 \pm 1.70$ & $6.5-12$ \\
$20-29$ & $8 \cdot 50 \pm 2 \cdot 53$ & $5-15$ \\
$30-39$ & $9 \cdot 05 \pm 1 \cdot 80$ & $5-13$ \\
$40-49$ & $12 \cdot 25 \pm 4 \cdot 10$ & $7-21$ \\
$50-59$ & $14 \cdot 13 \pm 9 \cdot 22$ & $7-50$ \\
$60-69$ & $16 \cdot 80 \pm 8 \cdot 41$ & $8-45$ \\
\hline
\end{tabular}




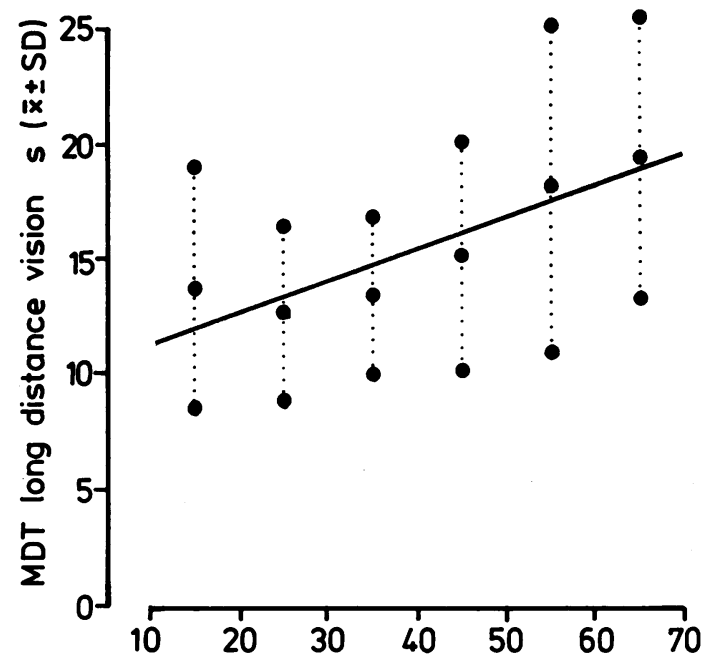

Fig. 1A

Age groups

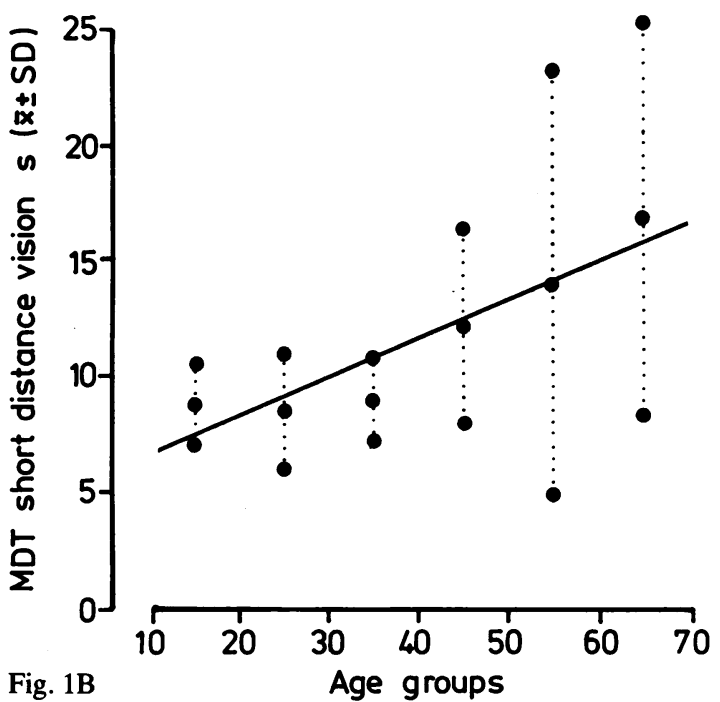

Fig. 1A Analysis of the distribution of means and standard deviations related to recovery time of the MDT for long distance vision, in the different age groups, by the linear correlation method. $r=0 \cdot 902 ; \bar{x}=-75 \cdot 46 ; y=9 \cdot 81$.

Fig. 1B Analysis of the distribution of the means and standard deviations related to recovery time of the MDT for short distance vision, in the different age groups, by the linear correlation method. $r=0 \cdot 94 ; \bar{x}=-31 \cdot 3 ; y=5.01$.

subjects under 40 years of age and those aged 40 and over (Table 5).

Figs. 2A and 2B show a better distribution of the percentage of eyes towards the lowest values.

The MDT was not influenced by the diameter of the pupil when the pupil is mydriatic and when the test is being made on long distance vision; however, the recovery time for short distance vision is longer. The MDT values with a miotic pupil showed a significant reduction in the recovery time, both for long distance vision and short distance vision, when these values were compared with those of a normal pupil and without the application of any type of pharmaceutical product to the eyes (Table 6).

\section{Discussion}

The MDT is an easy test to perform. It can be done

Table $5 M D T$ results related to age: under 40 years and 40 years and over

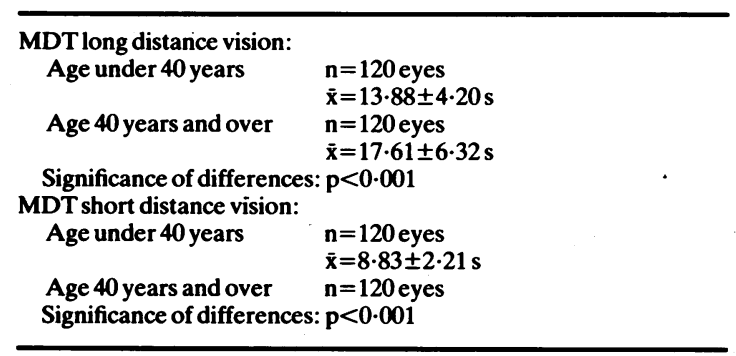

quickly (under 3 minutes) and its results can be repeated with a minimum of collaboration from the patient.

Most authors ${ }^{126-8}$ have used the light of their ophthalmoscope to produce the dazzling, varying the light exposure from 15 seconds ${ }^{7}$ to 1 minute. ${ }^{8}$ Although some of them ${ }^{127}$ place no importance on, or at least do not report, the intensity of the light, others vary the light's intensity. Forsius ${ }^{6}$ used 2145 lux, previously adapting the patient to the darkness for a one-hour period; and Tiburtius ${ }^{8}$ used an intensity of 50 lux. Glaser ${ }^{9}$ used a light source consisting of a light bulb which produced 2340 lux instead of an ophthalmoscope. We used a conventional electronic flash, like Lemrini and Carreras, ${ }^{3}$ as this technique is faster and it readily produces a true dazzling of the macula; in addition there is no need for exceptional collaboration by the subject being examined. In contrast, both the light bulb used by Glaser', and especially an ophthalmoscope light,

Table 6 MDT results related to the pupil diameter

\begin{tabular}{|c|c|}
\hline $\begin{array}{c}\text { MDT mydriasis (RE): } \\
\text { long distance vision: } \\
n=65 \text { eyes } \\
\bar{x}=15 \cdot 83 \pm 9 \cdot 78 \mathrm{~s} \\
\text { range: } 6-70 \mathrm{~s} \\
\text { short distance vision: } \\
n=65 \text { eyes } \\
\overline{\mathbf{x}}=14 \cdot 20 \pm 19 \cdot 83 \mathrm{~s} \\
\text { range: } 4 \cdot 5-115 \mathrm{~s}\end{array}$ & $\begin{array}{l}\text { MDT miosis (LE): } \\
\text { long distance vision: } \\
n=65 \text { eyes } \\
\bar{x}=12 \cdot 75 \pm 7 \cdot 37 \mathrm{~s} \\
\text { range: } 5-63 \mathrm{~s} \\
\text { short distance vision: } \\
n=65 \text { eyes } \\
\overline{\mathrm{x}}=9 \cdot 96 \pm 6.13 \mathrm{~s} \\
\text { range: } 4-36 \mathrm{~s}\end{array}$ \\
\hline
\end{tabular}




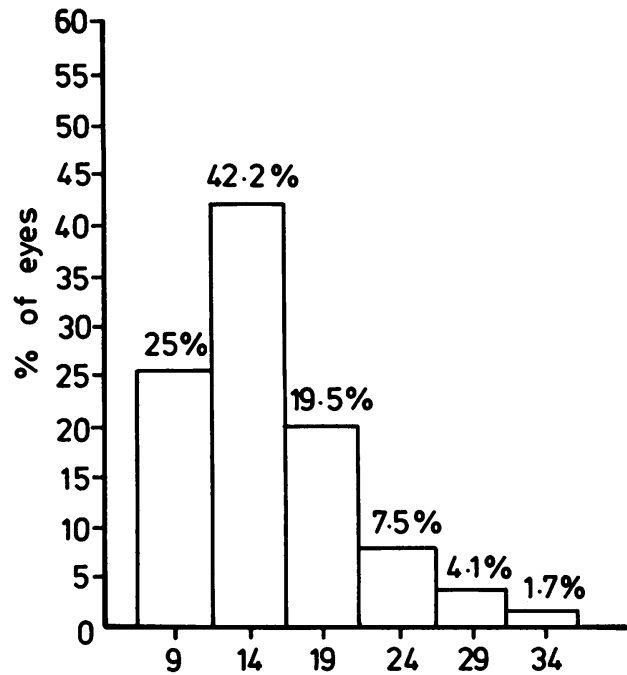

Fig. 2A MDT long distance vision (s)

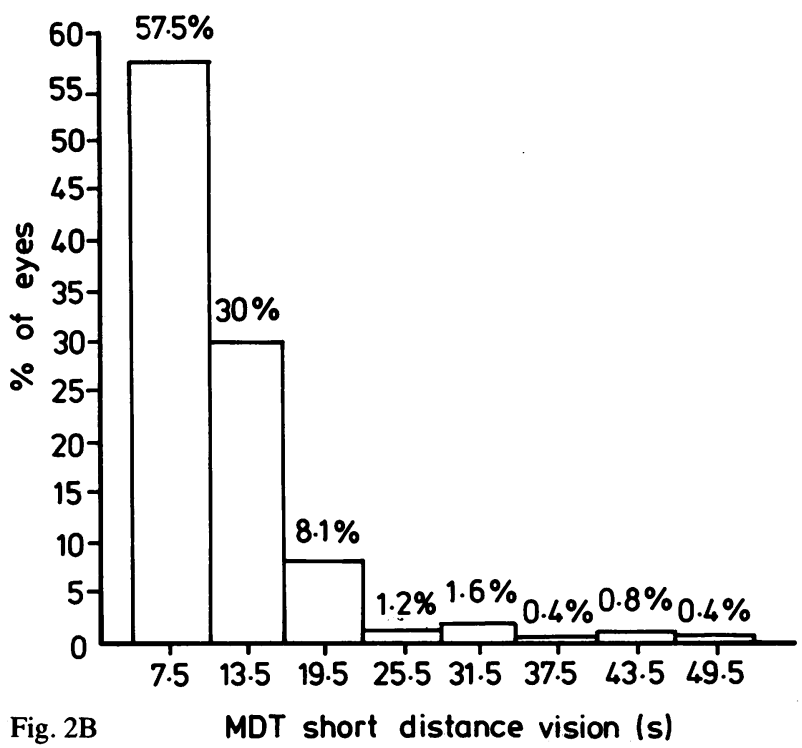

Fig. 2B MDT short distance vision (s)

Fig. 2A Histogram of frequencies of recovery time of the MDT for long distance vision, on 240 healthy eyes, with a mean of $15 \cdot 49 \mathrm{~s}$ and $S D 5 \cdot 76 \mathrm{~s}$.

Fig. 2B Histogram of frequencies of recovery time of the MDT for short distance vision, on 240 healthy eyes, with a mean of $11 \cdot 61$ s and SD 6.30s.

require a greater amount of patient collaboration, because he must concentrate his attention on the light source constantly for a period which varies from 10 to 60 seconds. Moreover the dazzling is possibly less. On the other hand the use of the conventional electronic flash, proposed by Lemrini and Carreras, ${ }^{3}$ avoids the sophisticated instruments like those used by Severin and his collaborators ${ }^{10}$ which, although they are more precise, do not invalidate our results, in addition to their being more difficult to use under the conditions of routine clinical examinations.

The instruments used by Severin and his collaborators $^{10}$ consist of a Meyer-Swickerath Zeiss light coagulator, a Goldmann-Weekers adaptometer, and a shutter, require in addition a -10 dioptre lens to diverge the beam of light and to light up the entire retina. This is not entirely necessary because the MDT really explores the macular visual acuity, and the lighting of the macula can be done perfectly well with a flash on which the patient focuses his eyes directly, thus making the use of a diverging lens unnecessary.

The mean value of the MDT for long distance vision (15.49 s) falls within the figures considered normal in published reports, ${ }^{1-12}$ with ours being the second lowest after those of Lemrini and his collaborators. ${ }^{3-5}$ This means that the reactions are more or less comparable and that they fall within similar values, with the values obtained depending on the type of light source used and on the method followed. In addition the age of the population on which the study is made must be taken into account, as we have shown that the recovery time following the dazzling is longer as the age of the subject increases, which has been pointed out by other authors, ${ }^{3-56810-12}$ though Glaser ${ }^{9}$ did not find that the MDT increases signficantly with age. It must be pointed out that the standard deviations increase simultaneously with the increase in the mean recovery time of the MDT with age. This increase in the mean value of the MDT with age is one more indicator of the involutional senile phenomenon, to which eyes are no exception. We must not forget the modifications which are produced with aging on the Bruch membrane complex and pigmentary epithelium. ${ }^{13-16}$ Neither the sex of the subject nor the eye studied (the right eye or the left eye) has any influence on the results of the MDT though Forsius ${ }^{6}$ found that in females the values are higher in the 10 to 39 -year-old group.

From what we have previously stated, and taking into account that the test is independent of other different age parameters, we consider, as the criterion of normality, that in eyes to which no pharmaceutical product has been applied those values which fall between the mean and a standard deviation (69\% probability) are probably normal, and that those which fall between the mean and two standard deviations (95\% probability) in each age group are truly normal. However, in absolute terms 
values greater than 32 seconds could be considered pathological. Or, if we compare the difference of the MDT in each eye of the same subject, for a probability index of $95 \%$ it is possible to accept differences between the right and left eye of up to 15.61 seconds for the first three decades and 22.15 seconds for the fourth, fifth, and sixth decades of life.

The dilatation of the pupil from 7 to $8 \mathrm{~mm}$ does not significantly modify the results of the MDT but miosis does. Miosis reduces the recovery time $\bar{x}=12.75 \mathrm{~s}$ ), though it does not reach the figures given by Severin and his collaborators, ${ }^{10}$ who refers to a reduction of up to $50 \%$. This would be a factor to consider with patients on miotics. The difference between mydriasis and miosis is difficult to explain, though the influential factors are the smaller amount of light that passes through a closed pupil, with a less dazzling effect, and the action itself of the stenopaeic hole which miosis of the pupil brings about.

The MDT performed for short distance vision, like that for long distance vision, shows no significant differences in the results in relation to which eye is explored, right or left, or the sex of the subject. It also increases progressively with age. There are significant differences between the subjects under 40 and those aged 40 and over. In addition the recovery times are reduced with miosis of the pupil.

If all the results obtained for short distance vision are compared with those for long distance vision, it can be observed that in all of the parameters analysed the reactions of the MDT are significantly reduced, which indicates a variability in the test according to whether the analysis is made at a short or at a long distance. These discrepancies, which are repeated in the different subjects analysed, could be due in part to the larger size of the retinal image in short distance vision - thus a greater clarity - and the reduction of the diameter of the pupil which is brought about on looking at something at a short distance (we have previously commented on how the MDT is reduced at a long distance with miosis), and to other factors such as the angular value of the optotype for short distance vision, brightness, etc.

There are no reports analysing the MDT for short distance vision, but since the results are homogeneous and this is a macular exploration test, its study in relation to short distance vision would seem logical, given the fact that there are existing differences in relation to long distance-short distance vision, which the MDT can clarify.

Although the purpose of this work is not the study of the MDT in macular pathology (this will form part of a second publication), we have observed cases of central serous retinopathy in which the MDT is pathologically prolonged, both for long distance vision and short distance vision. However, as regards short distance vision, the recovery time is double that of long distance vision when, as we have already seen, under physiological conditions the normal situation is the reduction of the recovery time for short distance vision.

\section{References}

1 Bailliart JP. L'examen funcionnel de la macula. Bull Soc Ophtalmol Fr 1954; 4: 52-8.

2 Chilaris GA. Recovery time after macular illumination as a diagnostic and prognostic test. Am J Ophthalmol 1962; 53: 311-4.

3 Lemrini F, Carreras B Jr. Test de deslumbramiento I. Valores normales. Arch Soc Esp Oftalmol 1982; 43: 392-6.

4 Lemrini F, Carreras B Jr. Test de deslumbramiento II. Valoración clínica en afecciones de la máxula y del nervio óptico. Arch Soc Esp Oftalmol 1982; 43: 517-22.

5 Lemrini F, Carreras B Jr. Test d'éblouissment. Bull Soc Ophtalmol Fr 1983; 94: 373-7.

6 Forsius H, Krause U, Eriksson AW. Dazzling test in central serous retinopathy. Acta Ophthalmol (KGL) 1963; 41: 25-32.

7 Magder H. Test for central serous retinopathy. Am J Ophthalmol 1960; 49: 147-50.

8 Tiburtius HF. Der Blendungstest in Klinik und Praxis. Graefes Arch Klin Exp Ophthalmol 1969; 178: 333-48.

9 Glaser JS, Savino PJ, Sumers KD, McDonald SA, Knighton RW. The photostress test in the clinical assessment of visual function. Am J Ophthalmol 1977; 83: 255-60.

10 Severin SL, Harper JY, Culver JF. Photostress test for evaluation of macular function. Am J Ophthalmol 1963; 70: 593-5.

11 Severin SL, Tour RL, Kershaw RH. Macular function and the photostress test 1. Arch Ophthalmol 1967; 77: 2-7.

12 Severin SL, Tour RL, Kershaw RH. Macular function and the photostress test 2. Arch Ophthalmol 1967; 77: 163-7.

13 Hogan MJ. Bruch's membrane and disease of the macula. Role of elastic tissue and collagen. Trans Ophthalmol Soc UK 1967; 87: $113-61$.

14 Hogan MJ, Alvarado J. Studies of the human macula. Arch Ophthalmol 1967; 77: 410-20.

15 Hogan MJ. Role of the retinal pigment epithelium in macular disease. Ophthalmology (Rochester) 1972; 76: 64-80.

16 Adler J. Physiology of the eyes. Buenos Aires, Panamericana Editorial: 1980; 15: 385-97.

Accepted for publication 12 July 1985. 